\title{
EL ARTE APOLÍNEO Y EL ARTE DIONISÍACO EN EL CASO MOREL, DE RUBEM FONSECA
}

\author{
María Isabel Salazar Bohórquez \\ Universidad Industrial de Santander (Colombia) \\ mariaisb.1208@gmail.com
}

Recibido: 06/01/2021 - Aprobado: 05/04/2021 - Publicado: 30/07/2021

DOI: doi.org/10.17533/udea.lyl.n80a06

Resumen: Este artículo analiza la concepción del arte que expresan los personajes de El caso Morel (1973) y su influencia en la evolución de su comportamiento y el desarrollo de la trama, especialmente en el ámbito sexual. Se emplea como eje teórico la diferenciación nietzscheana entre el arte apolíneo y el dionisíaco. En la novela se configura un tipo de policial denominado «policial dionisíaco», dadas sus características afines a las de dicho concepto. La predilección de los personajes Morel y Joana por el arte dionisíaco los lleva a tener una vida transgresora que imita y se inspira en el arte.

Palabras clave: El caso Morel; Rubem Fonseca; arte apolíneo; arte dionisíaco.

\section{APOLLONIAN ART AND DIONYSIAN ART IN O CASO MOREL, BY RUBEM FONSECA}

\begin{abstract}
This article analyzes the conception of art expressed by the characters in The Morel Case and its influence in the evolution of their behavior and the development of the novel's plot, especially in the sexual aspect. Nietzschean differentiation between Apollonian and Dionysian art is used as a theoretical axis. In the novel a type of police is configured called «Dionysian Police», due to its affinity with the characteristics of such concept. The affinity these characters possess for Dionysian art leads them to have a transgressive life that imitates and is inspired by art.
\end{abstract}

Key words: $O$ caso Morel; Rubem Fonseca; Apollonian art; Dionysian art. 


\section{Introducción}

$\mathrm{R}$

ubem Fonseca se ha consolidado como uno de los principales exponentes de la literatura brasileña contemporánea. Desde su primera publicación en 1963, el autor brasileño se caracterizó por tratar en

su narrativa tópicos como la corrupción, la violencia, la marginalidad, la prostitución, la pornografía y los diferentes conflictos sociales que se viven en las ciudades. A pesar de la buena recepción que han tenido sus libros por parte del público, algunos han sido objeto de censura dentro de su país natal, debido a sus descripciones explícitas de tipo sexual. Con El caso Morel, publicado en 1973, Fonseca hizo su primera incursión en el género novelístico; se trata de una narrativa policial que sirve de excusa para la reflexión sobre el arte, la literatura, la sexualidad y la figura femenina.

Gracias a Rubem Fonseca, el género policiaco adquiere relevancia en Brasil, pues, tal como lo explica Pellegrini (2014), previo a este escritor el género no gozaba de muy buena acogida en este país, «pode-se afirmar que apenas a partir dos anos 60 o gênero policial consolidou-se, encontrando um autor, Rubem Fonseca, que lhe deu forma definitiva e cores nacionais, conquistando muitos leitores e críticos, tornando-se uma espécie de matriz para vários outros contemporâneos» (como se citó en Comellas, 2014, p. 52). El éxito de la narrativa policiaca de Fonseca radica en el quiebre que realiza entre la llamada literatura erudita y la popular, mezclando elementos característicos de las dos y realizando así «uma aposta estética e moral que vai muito além de um particular intuito de épater les bourgeois» (Comellas, 2014, p. 53); de esta manera, Fonseca elimina todo tipo de barreras para que un público cada vez más amplio y variado acceda con interés a su literatura, la cual, bajo la apariencia de obras de consumo masivo, invita al lector a entender de manera crítica la sociedad en la que se encuentra inmerso.

Sumado a ello, la literatura de Rubem Fonseca se caracteriza por presentar una visión crítica de los diversos temas que aborda, empleando, en muchos casos, el discurso literario como una «indagación acerca de la realidad, indagación cuya finalidad no es resolver ningún tipo de problemas sociales» (Tello, 2004, p. 7); por eso, el hecho de abordar los aspectos más oscuros de las sociedades desde el frívolo lente de quien observa estos fenómenos en su cotidianidad repercute en que, más que respuestas, los lectores de Fonseca encuentren en su literatura una nueva perspectiva de la vida que lo lleva a cuestionar su propia realidad.

Dada la importancia que adquiere la violencia, la descomposición social dentro del ámbito urbano, la sexualidad, lo policial y lo grotesco en su narrativa, la mayoría de crítica existente sobre la literatura de Rubem Fonseca se enfoca en la descripción del papel que ejercen estos aspectos, especialmente en sus cuentos. Entre los estudios recientes más destacados se encuentran los realizados por Rejany (1999), Gonzáles (2003), Mendoza (2003), Tornquist (2007), López (2007) y Follain (2009), quienes, a nivel general, centran sus análisis en el tratamiento que le da Fonseca a la figura detectivesca, la violencia urbana y la sexualidad en determinadas obras. En cuanto a la crítica que se ha desarrollado en torno a El caso Morel (1973), es necesario destacar que los estudios son escasos y que la mayoría de estos se encuentran en portugués; por tanto, se deduce que la obra ha despertado poco 


\section{El arte apolíneo y el arte dionisíaco en El caso Morel, de Rubem Fonseca}

interés para ser analizada a nivel internacional.

Una de las investigaciones más amplias que se encuentra sobre El caso Morel es la tesis de maestría de Tello Garrido (1993), quien analiza la obra del escritor brasileño a partir de cuatro enfoques. En primer lugar, realiza una descripción de los fenómenos de la sexualidad, el erotismo y la pornografía en la narrativa fonsequiana. En segundo lugar, aborda la violencia desde lo que él denomina «estética de la misantropía», término que encuentra sentido en el hecho de que los héroes solitarios en Fonseca tiendan a buscar el placer a través del dolor, como recordatorio de su vitalidad y como recurso para su propia exaltación. En tercer lugar, estudia el relato policial a partir de dos personajes recurrentes: Mandrake y Vilela.

Finalmente, Tello Garrido (1993) señala a Morel y a Vilela como personajes que se encuentran en constante reflexión sobre su trabajo artístico y sobre las limitaciones que imponen el público y la crítica a este; de este modo, el autor analiza la literatura como crítica de la literatura en la obra fonsequiana y menciona las dos historias que desarrolla la novela. Este último aspecto es abarcado también por Darc Ribeiro (2001), quien le atribuye el carácter de fragmentaria, dada la presencia de dos narrativas en la trama: la primera, una voz impersonal que se centra en las conversaciones entre Vilela, Matos y Morel; la segunda, la novela de este último, escrita en primera persona.

Por su parte, Cardozo Garzón (2009) aborda la violencia sexual en la obra desde una perspectiva estética, analizando la influencia del Marqués de Sade como autor pionero en este tipo de literatura. Así, establece una diferenciación entre la sexualidad animal y el erotismo, y concluye que estos dos conceptos están íntimamente relacionados, pues, a pesar de que es posible «encontrar momentos de sexualidad sin erotismo, en donde la interioridad del ser desaparece y solo queda su animalidad, es decir cuando deja de ser racional» (p. 49), no se puede desligar el erotismo de la sexualidad animal.

Además, Cardozo Garzón (2009) señala que, tanto en la obra del Marqués de Sade como en la de Rubem Fonseca, el tratamiento de la violencia se presenta de manera progresiva; en el caso de Paul Morel, esto sucede de modo paralelo al ámbito sexual, pues «el contenido de la violencia también lo es [progresivo] en la novela, similar que con el lenguaje sexual que se va volviendo más violento» (p. 56). Por otra parte, indica que conforme van evolucionando las experiencias sexuales, el acto carnal involucra cada vez más una racionalización previa, volviéndose más consciente y meditado. Así, el placer de los personajes se centra en la transgresión y la sexualidad se convierte en una especie de ritual; sin embargo, en oposición a lo considerado por Cardozo, es necesario analizar que, si bien los personajes sí son conscientes e incluso Morel reflexiona sobre la transgresión, no puede decirse que durante las relaciones que mantiene con Joana premedite todas sus acciones y sea capaz de controlar sus actos, por lo que su actuar puede ser interpretado de una manera irracional y no consecuente.

Por su parte, Darc Ribeiro (2001) realiza un análisis histórico de la importancia y funcionalidad del «personajeescritor» en la novela contemporánea para, posteriormente, destacar la importancia que adquiere la subjetividad de algunos personajes fonsequianos dentro del ámbito investigativo, llegando a objetivarse los puntos de vista particulares; no obstante, el autor no hace un análisis exhaustivo de los aspectos en los que Fonseca innova. Por 
El arte apolíneo y el arte dionisíaco en El caso Morel, de Rubem Fonseca

otro lado, Rocha Ribeiro (2012) realiza una descripción general de la narrativa de Fonseca y enfoca su análisis en la metaficcionalidad, señalando la composición en capas de la novela, que crea la sensación de mise en abyme; menciona, además, la influencia del género del guion cinematográfico en el lenguaje narrativo empleado en $\mathrm{El}$ caso Morel y hace una contextualización de la importancia del aspecto comercial en la escena cultural de la década de los setenta.

Por lo anterior, se hace evidente que la crítica sobre El caso Morel gira en torno a algunos aspectos generales que han sido comúnmente analizados en la narrativa de Fonseca, como la metaficcionalidad, el género policiaco, la violencia y la sexualidad; por tanto, se concluye que existe un vacío en el análisis de la influencia del arte en la novela.

\section{La imagen en la literatura}

El caso Morel es una novela con un amplio marco referencial, que alude constantemente a textos de diferente índole, bien sea cinematográficos, literarios o pictóricos. Este último tipo de intertexto ha sido estudiado por la crítica bajo el término écfrasis, «la cual pretende definir la voz de la literatura en el diálogo entre las artes» (Robillard, 2011, pp. 27-28). Por su parte, Rancière (2011) propone el concepto de frase-imagen; este sintagma, que une dos órdenes sensoriales, «es la unidad que desdobla la fuerza caótica de la gran parataxis en potencia frástica de continuidad y en potencia de imagen de ruptura» (p. 63); así, la palabra cumple la función de encadenar y la imagen de interrumpir el discurso.

No obstante, la comprensión de las relaciones que se establecen a partir de dicha intertextualidad implica unos conocimientos específicos previos por parte del lector para que logre interpretar y traducir los significados que adquiere el fenómeno dentro de la obra. Así, la inserción de una referencia visual dentro de las artes verbales implica que el lector logre remitirse a los vínculos semánticos que supone la écfrasis; según Rancière (2011):

La potencia de la frase-imagen que une las heterogeneidades es entonces la de la separación y el choque que revela el secreto de un mundo, es decir, el otro mundo, cuya ley se impone detrás de sus apariencias anodinas o gloriosas (p. 72).

El diálogo entre estos dos tipos de arte puede desembocar en nuevas interpretaciones de cada texto, ya que «el texto visual, por su propia materialidad, así como por todas las otras significaciones potenciales, opone resistencia a la resignificación que el texto ecfrástico opera, produciéndose así interesantes efectos de sentido irónico [...] o simbólico» (Pimentel, 2003, p. 287). 


\section{El arte apolíneo y el dionisíaco en El caso Morel}

Dentro de la novela se establecen dos tipos de arte: el clásico, que es tachado por Joana y Morel, los personajes principales, como superfluo, catalogado por Joana como «la basura clásica de los museos» (Fonseca, 2015, p. 66), con lo que demuestra su desprecio; y, por otro lado, el arte de vanguardia, que va acorde con el criterio estético de estos al ser más reflexivo, el arte con el que se siente identificado Morel y con el que aspira Joana en su expresión creativa. Esta categorización se asemeja a la dicotomía establecida por Nietzsche (2000) entre el arte apolíneo y el dionisíaco. Por un lado, «la mirada, lo bello, la apariencia, delimitan el ámbito del arte apolíneo; es el mundo transfigurado del ojo, que, en sueños, con los párpados cerrados, crea artísticamente» (p. 255); se trata de un arte controlado, racional, en el que no puede faltar «la esencia de Apolo: aquella mesurada limitación, aquel estar libre de las emociones más salvajes, aquella sabiduría y sosiego del dios-escultor» (p. 245). Esto significa que lo apolíneo en el arte representa el equilibrio, la perfección, lo racional; de este modo, el artista apolíneo centra tanto su atención en el control de la forma, como en realizar una copia de la realidad, dejando de lado su propia interpretación del mundo.

En este sentido, Nietzsche señala que «la finalidad más íntima de una cultura orientada hacia la apariencia y la mesura solo puede ser, en efecto, el encubrimiento de la verdad» (p. 257); es precisamente este sesgo, y la ausencia de un significado latente, lo que critica Morel al arte clásico. Dicho personaje asocia este tipo de arte con la burguesía, manifestando que «a los ricos siempre les gustan los artistas visuales, son inofensivos» (Fonseca, 2015, p. 114); esta élite, según Morel, se dedica a seguir masas, pues su criterio artístico coincide con las obras que los críticos y connaisseurs destacan y ven el arte como un símbolo de estatus. Siguiendo este parecer, Morel le resta importancia a la creación artística de algunos autores de gran prestigio al mencionar que prefiere «la reproducción del trabajo de un artista que me guste a un original mediocre» (p. 70).

El concepto negativo que tiene Morel sobre el arte clásico lo lleva a afirmar, como una de las notas aisladas que conforman la narración de su novela, que «en todo el Louvre solo se salva la Batalla de Uccello. Lo demás es basura» (p. 57). Por otra parte, considera a su colega Elisa como primitiva, pues, mientras él juzga el arte desde una perspectiva decadente y cree que ya no existe tal cosa, ella es «una persona que solo ve la superficie de las cosas» (p. 57), es decir, una artista apolínea e ingenua que se centra en la forma de los fenómenos artísticos, en la apariencia y no tanto en lo que estos puedan llegar a significar ni en la crítica social que puedan llegar a establecer.

A pesar de que el ideal de Morel es un arte transgresor, cae en la debilidad de hacer lo que los demás esperan de él, con el objetivo de ganar premios y recibir elogios de la crítica para luego vender sus obras de poco valor artístico a los burgueses y obtener así una remuneración que le permita vivir cómodamente, «como si fuese un perro amaestrado, uno de esos animales de circo que ejecutan sus pobres trucos para ganar un poco de azúcar» (Fonseca, 2015, p. 198). Morel pretende ser un artista de vanguardia que se interesa únicamente en lo que expresa mediante su arte, sin importarle la recepción de los críticos ignorantes, pero que en realidad también busca la 


\section{El arte apolíneo y el arte dionisíaco en El caso Morel, de Rubem Fonseca}

aceptación de su trabajo artístico, razón por la cual, cuando decide incursionar en la escritura, busca ayuda de una autoridad en el tema y le expresa su deseo por tener la certeza de que su libro será publicado. Esto sugiere una concepción pragmática del arte; de este modo, lo que le interesa al personaje no es el proceso de creación, ni el significado que imprime en sus obras, sino la visibilidad que estas puedan llegar a obtener. Por eso, Morel no quiere desperdiciar su tiempo y esfuerzo en algo que no le garantice cierto reconocimiento.

Por otra parte, se encuentra el arte dionisíaco, cuya desmesura «se revelaba a la vez en placer y dolor y conocimiento. Todo lo que hasta ese momento era considerado como límite, como determinación de la mesura, demostró ser aquí una apariencia artificial: la "desmesura" se desveló como verdad» (Nietzsche, 2000, p. 258). Se trata de un arte destructivo que no encuentra placer en lo bello, sino que se caracteriza por su irregularidad, impulsividad y reveladora visión del mundo; es un arte que «descansa en el juego con la embriaguez, con el éxtasis» (p. 246). Este deseo por transgredir las normas se observa en Morel incluso en el ámbito de la escritura, pues expresa que, si no fuera fotógrafo y pintor, sería escritor y, en ese caso, su proyecto de libro sería uno de cuatrocientas páginas en las que esté escrito:

«A. M. Carvalho, ochenta años, come filete con papas fritas. Su nieto, dieciséis años, come el mismo plato. Inversiones diferentes. A. M. Carvalho, ochenta años, come filete con papas fritas», etc. Del principio a la página cuatrocientos, un único párrafo, compacto, coherente, consonante (Fonseca, 2015, p. 45).

Dado su carácter crítico, el arte dionisíaco deja de lado la realidad objetiva y el artista se centra en su propia percepción de los fenómenos, tal como una nota aislada del libro de Morel comenta sobre el arte de escribir, «el escritor tiende a una conciencia más aguda de sí mismo en el acto de crear» (p. 101). Se establece entonces el arte como expresión «de los estímulos que provienen del interior del cuerpo y alcanzan el alma» (Freud, 1992, p. 117), como manifestación del inconsciente del autor. Un arte desenfrenado, pulsional, instintivo, irracional en el que el artista expresa su criterio ante diversas problemáticas de la sociedad y la vida.

Para Morel, «la función real del arte, más que exprimir sentimiento, es transmitir comprensión» (Fonseca, 2015, p. 74). En este sentido, podría afirmarse que el ideal de arte para dicho personaje es aquel que produzca un efecto de extrañamiento y, por tanto, logre una transformación en el espectador; un arte que comunique lo más íntimo de su creador y su relación con el mundo, de tal manera que, según Morel, «Si la realidad pudiese entrar en contacto directo con nuestro inconsciente, si pudiéramos comunicarnos inmediatamente con las cosas y con nosotros mismos probablemente el arte sería inútil, o mejor dicho, todos seríamos artistas» (p. 109).

Es por este carácter subjetivo y pulsional que él mismo siente angustia ante la sensación de vacío: «mi única salida era soldar chatarra, pegar, simular, golpear, copiar mientras pudiera» (p. 17); no puede exteriorizar su ser porque simplemente no tiene nada para comunicar, no siente nada, su relación con el mundo está rota. En lugar de ello, manifiesta su desilusión por el contexto en el que vive, por todos los fenómenos sociales que observa y la falta de criticidad dentro de la gran mayoría de consumidores de arte, lo que le hace pensar que se pierde el sentido de su oficio. Igualmente, Morel se siente incapaz de realizar un arte novedoso, pues tiene tanta información en su 
El arte apolíneo y el arte dionisíaco en El caso Morel, de Rubem Fonseca

cerebro, al cual él mismo relaciona con un palimpsesto, que termina por convertirse en «"una persona incapaz de un pensamiento original, uno, solo uno"» (p. 88).

Por otra parte, a pesar de que Morel se incline por artistas de vanguardia como Man Ray (Emmanuel Radnitzky) o Víctor Vasarely, que expresan mediante su arte una interpretación personal de la vida y una crítica a diferentes fenómenos sociales, su deseo de fama lo lleva a ir, en algunas ocasiones, en contra de sus propios principios y realizar exactamente lo que tanto critica de los artistas de masas; este hecho influye considerablemente en su visión decadente del arte, pues Morel es consciente de que incluso él mismo cae en la debilidad de poner sus propios intereses por encima del verdadero sentido de su oficio.

\section{La influencia del arte en la evolución de Paul y Joana (Heloísa)}

A lo largo de la novela se revela la predilección artística de Paul y Joana a partir de discusiones que tienen, tanto entre sí como con otros personajes, sobre algunas obras y autores. De esta manera, existen algunas referencias visuales que tienen una gran relevancia en el desarrollo del actuar y pensar de estos personajes.

En este sentido, la primera pintura por resaltar es La batalla de San Romano (1456) de Paolo Uccello, la cual, si bien no cumple a cabalidad con las características del arte dionisíaco, sí expresa una de las tensiones más inherentes del ser humano, lo cual le proporciona el valor suficiente para sobresalir entre las demás obras de su categoría. No en vano, Morel menciona el cuadro del artista italiano como única obra de valor en el Museo del Louvre, pues representa una de las principales pulsiones del ser humano: su propensión a la violencia. En concreto, se trata de la pulsión de muerte que, según la definición de Laplanche y Pontalis (2004), se contrapone «a las pulsiones de vida y tiende a la reducción absoluta de las tensiones, es decir, a devolver al ser vivo al estado inorgánico. / Las pulsiones de muerte se dirigen primeramente hacia el interior y tienden a la autodestrucción; secundariamente se dirigirían hacia el exterior, manifestándose entonces en forma de pulsión agresiva o destructiva» (p. 336).

Vale resaltar que, en cuanto al ámbito sexual de Morel, si bien siente placer hiriendo a Joana por petición de ella misma, es solo hasta el final que experimenta la sensación de ser golpeado, cuando los policías lo atacan a la fuerza: «¡Estaba vivo! Qué sensación tan buena, el dolor pasando. ¡Lo mejor de este mundo!» (Fonseca, 2015, p. 131). En este caso, su placer no se encuentra en el impacto del golpe, sino en la liberación del dolor. Frente a esta pulsión, el mismo personaje reflexiona en su novela al comentar, como nota aislada que introduce a este episodio, que «los humanos llevamos dentro de nosotros las semillas, continuamente alimentadas, de nuestra propia destrucción. Necesitamos amar, así como odiar. Destruir, y también crear y proteger» (p. 130). Así pues, Morel no disfruta en ser golpeado sino en «destruir» a Joana, infringiéndole el dolor que ella le pide con frenesí, incluso podría decirse que esta acción representa una manifestación del amor que siente por ella.

Por otra parte, hay que resaltar que el criterio artístico de Joana se encuentra altamente influenciado por las consideraciones de Morel; de esta manera, en una carta, le confiesa a Paul su obsesión con El baño turco (1856) de Jean-Auguste-Dominique Ingres, no sin manifestarle vergüenza por este hecho: «ya sabes, decía ella, quiero 


\section{El arte apolíneo y el arte dionisíaco en El caso Morel, de Rubem Fonseca}

hacer cosas de vanguardia, como tú, la basura clásica de los museos no me interesa, pero me dieron unas ganas irresistibles de pintar también mi Baño Turco, como lo hizo Picasso» (Fonseca, 2015, p. 66). Así, Joana expresa esta obsesión como algo impulsivo, que no coincide con sus gustos y, por ende, carece por completo de sentido.

A pesar de no comprender el origen de su atracción, se deja llevar por el deseo de su inconsciente y dedica mucho tiempo de su estancia en París a ver el cuadro, reproduciendo en su carta una original narración del mismo, que, lejos de describir la perfección del trazo de Ingres, se dedica a analizar el estado anímico, físico y social de los personajes que se encuentran inmersos en la escena. Para ello, Joana infiere las diferentes posiciones jerárquicas que se establecen entre las mujeres $\mathrm{y}$, a partir de sus gestos, deduce los deseos que manifiestan; en este sentido, su interpretación de lo que muchos han considerado como la fracción más erótica del cuadro consiste en una écfrasis que, más que describir la escena, convierte a la pintura en un reflejo de sus propios deseos, de su anhelo por entregarse desenfrenadamente al placer sexual:

Las Dos Mujeres Abrazadas; una tiene el pelo castaño, lleva en la cabeza un adorno de piedras rojas y verdes, de rostro aristocrático destacado, inteligente, tranquilo, y la mano izquierda, mano posesiva, dominante, sádica agarrando con firmeza el pecho de la otra mujer. La Mujer de Fez transmite un aura de preparación: alguien que sabe lo que debe hacer y espera el momento propicio. La otra, la Mujer de Pecho Apretado es un ser voluptuoso, de ojos almendrados y la placidez de quien recién tuvo un orgasmo (p. 67).

Podría deducirse, entonces, por su conducta masoquista, que Joana no solo se siente identificada con la mujer a quien le aprietan el seno, sino que desea estar en su posición; por consiguiente, la pintura que realizó inspirada en El baño turco centra su atención en el pecho y la mano que lo sujeta, difuminando todo a su alrededor, pues «sólo se presienten los ojos de las otras mujeres. Un clima siniestro, misterioso, excitante» (p. 67).

Por otro lado, el cuadro pudo inspirar a Joana a la hora de proponerle a Morel cohabitar con varias mujeres ante su negativa de vivir únicamente con ella — «no tiene que ser una sola mujer. Puedes vivir con cuantas quieras, siempre y cuando yo sea una de ellas» (p. 76)_, pues, a pesar de que él insista en denominarla una familia moderna, desde la perspectiva de ella, Morel hace de su vida un harén. Por su parte, Morel parece constituir su hogar a imagen y semejanza de El baño turco, pues, tal como en la pintura, las mujeres seleccionadas para vivir en su casa pertenecen a diferentes clases sociales y poseen estilos de vida bastante dispares.

En primer lugar, Joana (Heloísa) es la joven hija de un embajador, perteneciente a la élite en la que vive cómodamente y sin necesidad de trabajar; no obstante, a pesar de su aparente erudición, dedica su vida únicamente al disfrute y aprendizaje informal del arte. Carmen (Lilian), por su parte, es una modelo y prostituta part time, cuya vida ha estado marcada por el abandono, el sufrimiento y la pobreza y quien, además, es madre de un niño de cinco años al que no puede cuidar sola. Ismenia (Aracy) es una pintora nä̈ve que vivió en la casa de infancia de Morel y cuyo trabajo es ampliamente reconocido en Europa, pero no tiene éxito en Brasil, de quien podría decirse que pertenece a una clase social media. Finalmente, Elisa Gonçalves (Marta Cunha) quien, si bien no vivió con Morel, sí frecuentaba la casa de este y participaba de los juegos que allí se organizaban; se trata de la infeliz 
El arte apolíneo y el arte dionisíaco en El caso Morel, de Rubem Fonseca

esposa de un hombre rico, del cual depende económicamente y a quien debe tolerarle todas las infidelidades para mantener su estatus social. Como en El baño turco, en el experimento familiar de Morel diferentes clases sociales conviven indiscriminadamente en un mismo escenario.

Otra de las obras con gran repercusión en la novela es la escultura de Man Ray, Le Cadeau (1921). Esta obra evoca la arquetípica imagen de los genitales femeninos simbolizada por la forma triangular de una plancha con chinchetas pegadas a su suela; por eso, al emplear y antropomorfizar un objeto doméstico común, Man Ray aprovecha la carga semántica de las asociaciones culturales preestablecidas para la plancha de manera tal que, sin negar su función original, se intensifique su peligrosidad (Schrock, 1996). De hecho, Morel parece inspirarse en esta y en otra escultura de Man Ray titulada Man, al crear las ilustraciones para la revista Venus R. B., como la del aparato reproductor masculino: «una especie de viga-émbolo-pistón-verga, en uno de los extremos una masa que al mismo tiempo parecía un diamante, aspectos de un ser humano y un glande; el otro extremo terminaba en un engranaje de resortes, ejes, embragues, tarugos» (Fonseca, 2015, p. 74).

Las implicaciones sádicas a las que alude la escultura citada son evidentes, pues, teniendo en cuenta el uso con el que se asocia una plancha, la inserción de la fila de tachuelas evoca la imagen de «clothing being ripped and shredded - a violation of and threatened assault on our most important physical and psychological barrier.» (Schrock, 1996, p. 27). Como símbolo de los genitales femeninos, las chinchetas «meticulously placed down the center visually divides the metaphorical labia while at the same time presenting a vicious row of teethtransforming the pubic triangle into the mythic vagina dentata.» (p. 27). Esta imagen mítica ha sido temida en diversas culturas, al ser interpretada como una amenaza para el órgano sexual masculino: «the vagina dentata became a symbol of what 19th-century men actually feared most, the "new woman" who de-sexes-or castrates.» (p. 27).

En este sentido, Paul Morel se constituye como un hombre que se aleja de todo compromiso serio con las mujeres, pero al mismo tiempo se sabe completamente dependiente de ellas. Este personaje tiene la actitud típica donjuanesca, pues nunca se niega ante la invitación de una mujer así se encuentre indispuesto, por lo que se cree conocedor de todas las tácticas seductoras y hace cualquier tipo de artimaña con tal de llevárselas a la cama, inclusive inventarse al personaje del profesor Khaiub y contratar a un actor para que lo interpretase en su reunión con Elisa; además, se siente orgulloso de sus atributos masculinos y busca exhibirse lo máximo posible mientras tiene una erección. No obstante, detesta la idea de ser controlado y, por el contrario, a pesar de que sintiera que todo estaba muerto entre él y su esposa, continúa conviviendo con Cristina simplemente porque eso lo hace sentirse dueño de ella, como si fuera su propiedad privada.

A partir de lo anterior y como resultado de evitar cualquier tipo de control sobre su vida, Morel evita establecer una relación de compromiso más allá del plano sexual con las mujeres a las que frecuenta, pues considera el matrimonio y las relaciones monógamas como un instrumento para reafirmar la ideología burguesa de la seguridad. Por estas razones se niega a vivir únicamente con Joana y expresa no tener ya «paciencia para vivir con una mujer de nuevo» (Fonseca, 2015, p.76). Siguiendo el análisis de Tello (1993), para quien «los signos de 


\section{El arte apolíneo y el arte dionisíaco en El caso Morel, de Rubem Fonseca}

la sexualidad en la obra de Fonseca ponen en evidencia el vacío de los individuos que en arranques desesperados pretenden entregarse al placer» (p. 39), se considera importante destacar que tanto Joana, desde su concupiscencia masoquista, como Morel, en medio de su apatía por el mundo, buscan desesperadamente un refugio en el placer sexual, con el objetivo de hallar significado a sus existencias.

Igualmente, estos personajes, al poner en duda todo lo establecido, se niegan a vivir dentro de las normas, dado que viven en una negación constante que los «lleva a una insignificancia» (Cardozo, 2009, p. 78), la que a su vez los conduce a una búsqueda constante que, generalmente, desemboca en «la violencia o el cinismo como formas de expresión vital» (p. 70); es así como la violencia se convierte no solo en un sinónimo de placer, sino en un medio para dar sentido y reafirmar su propia existencia.

A pesar de que Morel haya querido alejarse de Joana por sus preferencias sexuales — «Le pegué, le pegué, y después sentí una enorme repugnancia. No quise volver a verla por un buen tiempo» (p. 165) — y de que la considerara en algunas ocasiones una chiquilla ingenua, siempre regresaba a ella, cada vez consintiendo más en los gustos que ella imponía. Ahora bien, es justo en este ámbito en el que Morel se muestra más complaciente con Joana, pues le obedece en todo lo que pide sin refutar: «Joana quería ser golpeada, humillada, sodomizada, quería tener la cara manchada por mi semen. Le di en el gusto» (p. 45)- la obedece incluso sabiendo que cuando cede a sus peticiones él no logra llegar al orgasmo. Solo hasta los últimos encuentros de ellos Morel muestra oposición a satisfacer las peticiones de Joana, mas, sin tener éxito con su actitud y cediendo finalmente a los deseos de ella, y termina accediendo de manera tan desenfrenada que huye del lugar sintiendo repulsión por sí mismo, dejándola moribunda en la playa debido a la brutalidad de sus actos.

Por otra parte, el mismo personaje manifiesta una admiración por la independencia sexual que muestran las mujeres de su época, pues, si por un lado él se avergonzaba de revelarse desnudo mientras no tuviera una erección y le tenía lástima a su miembro caído, comparándolo con una tripa inerte, las mujeres «estaban cada vez más bonitas. Y más poderosas, pues no necesitaban de una erección para amar. Podían prenderse en la mitad. Cada vez estaba más difícil ser hombre en aquella época de transición» (p. 34). Al respecto, Gonçalves (2008) afirma que en la década de los sesenta empieza a darse un cambio de paradigma en cuanto al rol y las actitudes de la mujer. Por eso, el recato, la sumisión y la ingenuidad dejan de caracterizar a la imagen arquetípica femenina y se convierten en sus opuestos; de este modo, la mujer de esta época, que coincide con los años en que se desarrolla y publica la novela, empieza a ser «avançada, moderna, informada e independente» (p. 21).

Aparece entonces la concepción de una mujer más libre que pretende tomar el control en todos los ámbitos de su vida, situación que genera temor por parte del hombre, quien se siente disminuido e inseguro, pues, como bien lo afirma un personaje de Bufo \& Spallanzani (1987), el único aporte del hombre al mundo es «un carajo tieso. Vosotras en cambio, las mujeres, lo creasteis todo: el fuego, la rueda, la cerámica, la agricultura, la ciudad, el museo, la astronomía, la moda, la cocina, el placer, el arte» (p. 304). Así, cuando la mujer se autodetermina, «se torna não apenas um objeto de prazer, mas uma pessoa com quem o homem sente uma necessidade de competir, para se sentir existente, capaz» (Gonçalves, 2008, p. 36). De este modo, la mujer ya no busca en el hombre la 
El arte apolíneo y el arte dionisíaco en El caso Morel, de Rubem Fonseca

figura de protección y fuente de satisfacción sexual, ni muestra debilidad ante las típicas técnicas de seducción donjuanescas, sino que exige en el hombre otras aptitudes y cualidades; por ello, puede prescindir del hombre tanto en el ámbito sexual como en el sentimental al no seguir sosteniendo una relación de dependencia hacia este.

Con relación a esto, Joana presenta una actitud transgresora de los valores establecidos previos a la década de los sesenta en Brasil, pues busca huir de toda conducta que se relacione con los patrones y los estereotipos conservadores. Por eso, no solo deja de tener miedo a expresarse abiertamente sobre su sexualidad, ni a ser quien tiene la iniciativa en este aspecto, sino que busca exhibir el cambio de paradigma que se da al asumir su nueva posición sexual para ser escuchada y tomada en cuenta. Frente a esto, hay que resaltar que en la fiesta de élite a la que Morel y Joana asistieron, es ella quien le propone abandonar el lugar y tener relaciones sexuales; ante el poco convencimiento de Morel, quien se excusa en su aparente impotencia, ella busca persuadirlo al sugerir la inclusión de un elemento trascendental que cambia por completo la vida sexual de esta pareja: un látigo. Además de tomar la iniciativa, es ella misma quien se encarga de conseguir dicho objeto y de llegar a la casa de él para su encuentro.

Finalmente, cerca del punto culmen de su vida, Joana muestra una afinidad por el accionismo vienés, manifestando que «“E1 Baño Turco es una cosa del pasado, arte víscera, sangre, cuerpo, en eso estoy metida”. En ese momento el ideal de ella era Schwarzkogler, el artista que se amputó todo el cuerpo, comenzando por el pene, hasta morir» (Fonseca, 2015, p. 181). Este movimiento artístico, como afirma Soláns (2000), presentaba:

[...] el arte como terapia y liberación de las represiones sexuales, tanáticas y agresivas $-\mathrm{y}$ revolucionarias — el arte como política, es decir, como transformación del mundo, dentro del contexto ideológico de las revoluciones de mayo del 68, que conmocionaron a Europa y Norteamérica (p. 12).

Asimismo, como lo mencionan Amezcua y Sanz (2005), «sus acciones consistían en la exploración de las zonas prohibidas del cuerpo, la mente y el arte. Este autodenominado "anti-arte", al ser entendido como pura acción, pretendía romper definitivamente con el arte como contemplación y/o reflexión» (p. 26). Esto indica que el accionismo vienés concibe el arte como acción, como política, como protesta, como vivencia propia de todo lo que se desea expresar. En este sentido, deja de lado los elementos tradicionales con los que se trabajaba y plantea un arte en el que el cuerpo es el espacio principal de manifestación, en el que «los cuchillos se convierten en pinceles, el cuerpo en lienzo y la propia sangre en el pigmento» (p. 27). Por eso, los artistas pertenecientes a esta corriente artística solían presentar exhibiciones en las que se realizaban cortes, automutilaciones o autoelectrocutaciones (Amezcua \& Sanz, 2005). De esta manera, el accionismo vienés, como el arte dionisíaco, encuentra sentido en la desmesura, el placer, el dolor y el conocimiento, siendo a partir de este último aspecto que cobra sentido, pues es la consciencia de la descomposición social lo que impulsa al artista a crear y denunciar.

En este orden de ideas, según el criterio artístico de Joana, que parece evolucionar al mismo ritmo que sus desenfrenos sexuales, el mejor artista que conoce es un carnicero; se trata del padre de Sonia, una joven con quien ella y Morel mantuvieron relaciones sexuales y por cuyo discurso — la descripción del proceso para sacrificar animales_- Joana mostró gran interés, al punto de ir a la granja en que vivía Sonia y su padre, el carnicero, para 
El arte apolíneo y el arte dionisíaco en El caso Morel, de Rubem Fonseca

ver con sus propios ojos el sacrificio de animales, lo que para ella es toda una exhibición artística. Por tanto, es como si Joana prestara su cuerpo para que Morel hiciera arte con él, un arte pulsional y desenfrenado, en el que el artista no logra ser totalmente consciente de sus actos, un arte por el cual Joana termina perdiendo la vida: «Seguí dándole patadas mientras se reía y yo miraba la puesta de sol. Era algo lindo, indescriptible» (Fonseca, 2015, p. 124); así, la manera en que Morel describe los acontecimientos del último encuentro que mantuvo con Joana crea una ambigüedad sobre el objeto admirado, pues bien puede referirse al atardecer, como al escenario con Joana.

\section{El policial dionisiaco en El caso Morel}

Si bien este trabajo no pretende analizar a profundidad el tratamiento que le da Rubem Fonseca al ámbito detectivesco en su novela, se considera importante destacar que la investigación policial se presenta, acorde a los gustos artísticos de Morel y Joana, de una manera transgresora, ya que tiene un carácter de poca rigurosidad. Esta característica se hace recurrente en la obra de Fonseca, pues como lo menciona Tello (1993) en su tesis, el escritor «utiliza el paradigma del género policial para invertirlo, transgredirlo, problematizarlo o parodiarlo» (p. 200). Así, los lectores se encuentran ante la presencia de Vilela, un detective que desarrolla la investigación del crimen, principalmente a partir de las subjetividades del libro de Morel y del diario íntimo de Joana. Resulta curioso que el papel inicial de este detective sea el de orientar a Morel en su proceso de escritura, mas no el de emprender la pesquisa.

Por otra parte, el verdadero encargado del caso, el detective Matos, inculpa a Morel únicamente a partir del diario de Joana, sin desarrollar un proceso investigativo previo. Ni siquiera el hallazgo de este elemento representó un esfuerzo por parte del investigador, sino que fue dejado por una mujer «en un sobre con mi nombre [Matos]. Había una nota que decía: “El asesino es Paul Morel”. Así fue como llegamos a usted, nos 1legó, ni un mérito para nosotros..., pero bueno, lo que interesa son los resultados» (Fonseca, 2015, p. 129). El hecho de que Matos argumente la culpabilidad de Morel basado en un diario íntimo resulta incluso irrisorio, pues se trata de un texto cuyos acontecimientos narrados no pueden garantizarse como verídicos; por tanto, se establece el discurso literario como un medio fehaciente de percepción de la verdad, incluso más que la realidad misma (Tello, 2004). Este hecho pone de manifiesto la posibilidad de fracaso de la policía, pues existe la opción de que el detective reconstruya los hechos de manera errónea, no tanto por desconocimiento, sino más bien por carencia de investigación y corrupción; de este modo, la policía aparece como fuerza del caos, no como fuerza de seguridad.

A partir del anterior episodio, el detective Matos se aleja de la investigación, pero Vilela continúa realizando indagaciones, pues es quien siente que algo no cuadra con la resolución dada por Matos. Es por esto que Vilela descubre antes que Matos la incongruencia con los urubús, si en verdad es este animal el que le advierte a Félix la presencia de algo extraño en la playa, el cuerpo debía tener señas de picotazos cuando fue encontrado, marcas completamente ausentes en la escena del crimen; este descubrimiento lo lleva a comprender el engaño de Creuza para ocultar a Félix, quien, además de confesar la verdadera versión de los acontecimientos con el cuerpo de 
El arte apolíneo y el arte dionisíaco en El caso Morel, de Rubem Fonseca

Joana, admitió de inmediato que hacía ya un tiempo había hecho pasar por muerto a su esposo para evitarle el sufrimiento de la cárcel cuando fue condenado de nuevo por hurto; de este modo, la falta de comunicación entre los dos detectives, Matos y Vilela, hace que este último, al sentirse asediado por la policía que Matos envía en su búsqueda, prefiera suicidarse.

En concreto, en la lupa investigativa de Vilela se conjugan tres perspectivas que están dentro de su personalidad: la de abogado, la de policía y la de escritor. Por eso, el criterio de Vilela se da desde su visión «de detective que por “deformación profesional" piensa la realidad como un texto susceptible de ser leído y, como sus significaciones son múltiples, también interpretado» (Tello, 1993, p. 229); así, Vilela puede interpretar la realidad de un mismo hecho a partir de múltiples ramificaciones y perspectivas que se encuentran influenciadas por la subjetividad de la perspectiva del investigador.

Por otra parte, el proceso artístico de escritura se constituye en un elemento de reflexión que sirve de partida para el conocimiento de los personajes que busca reconstruir y comprender el pasado: «Morel se busca a sí mismo, pero quiere encontrarse inocente; Vilela busca a Joana, pero no como víctima (aunque desde el inicio se ha enterado de que está muerta) sino como objeto del deseo» (p. 222). Así, al igual que Joana con El baño turco, Vilela encuentra en el discurso de Morel un reflejo de sus propios deseos, pues busca en sus palabras aquellos elementos que considera más interesantes, los cuales no se encuentran vinculados con el desarrollo de la investigación, sino con los aspectos más íntimos de la relación que esta mantiene con Morel.

La escritura caótica de Morel se convierte entonces en el elemento central de la investigación, y Vilela, lejos de mostrar objetividad ante los hechos, empieza a involucrarse, de tal manera que genera una especie de atracción necrofílica por Joana y sus encuentros con Morel tienen cada vez más un carácter íntimo; Vilela busca toda la información que pueda recopilar de Joana, ya sea a través de películas, cartas u otros medios, y fantasea constantemente con una Joana que se dirige a él, incluso desde su condición de muerta, haciendo alusión a conversaciones con matices eróticos «mi cuerpo ahora es transparente, nunca has tocado el delicado pezón rosado de mi pecho y solo me ves si pasas una luz fuerte por dentro de mí» (Fonseca, 2015, p.191). Igualmente, el interés de Vilela porque Morel continúe con la escritura de su novela ya no radica en la investigación del crimen, sino en su deseo por saber cada vez más acerca de la joven muerta.

Ya no habla de lo que quisiera saber... El juego entre él y Heloísa, las regresiones infantiles, los mimetismos animales, las personificaciones, posesiones, abyecciones... Morel vestido con la ropa del padre de Heloísa, castigándola antes de ir, padre e hija, a la cama [...] Heloísa cortándole el cuello a Morel y él haciéndole lo mismo y después, abrazados, chupando uno la sangre del otro (p. 199).

A partir del fragmento anterior, se puede evidenciar un proceso de mimetización entre el detective y el investigado, semejanza en la que reflexiona el mismo Vilela al equiparar las condiciones de pobreza y soledad que ambos han experimentado a lo largo de sus vidas; igualmente, y como se evidencia en la anterior cita, él mismo siente una evolución semejante ante la perspectiva desde la cual considera la violencia: «El sadismo de Morel perturba a Vilela. Siente el mismo impulso vital hacia la violencia, no una salvaje manifestación de atavismo, sino 
El arte apolíneo y el arte dionisíaco en El caso Morel, de Rubem Fonseca

un deseo maduro y lúcido, que permitía a Morel la conciencia de la propia crueldad» (p. 153).

De esta manera, ambos personajes terminan pareciéndose tanto que hasta ejercen una influencia mutua en su estilo narrativo, como lo señala Matos al terminar de leer los manuscritos de Morel: «El tipo te imita, pensé que estaba leyendo tu último libro, es igualito» (p. 137). Esta semejanza es ya señalada por Darc (2001), quien destaca que este espejo a nivel ficticio crea una fusión de voces que marca el quiebre de la novela policial tradicional al dejar espacio a ambigüedades. Posiblemente, esta afinidad entre ellos hace que, al final, Vilela resuelva el caso de una manera bastante desconcertante:

La condena de Félix es un final perfecto para nuestra historia. Olvidemos que es inocente, saltó de la ventana con miedo (ya había sido arrestado y sabía lo que le esperaba). Olvidemos también que la mujer fue golpeada y que no cambió sus declaraciones. (¿Quién se agarraría a una mentira tan inútil?) (p. 204).

En este caso, Vilela habla en plural, pues se siente identificado e inmerso en la historia de Morel y, asimismo, responsable por su desenlace; por eso, la distinción entre estos dos personajes termina difuminándose a tal punto que ya no se logra comprender quién es quién, dado que «en realidad somos una sola persona y lo que uno siente, el otro también lo siente. Lógico. Por lo tanto, nuestro fin también es el mismo» (p. 204). Quizá, dada la obsesión que desarrolla el detective por Joana, Vilela habría querido estar en el lugar de Morel en todos los acontecimientos que este comparte con él a partir de su escritura.

Por otra parte, en la novela, el orden social no se reestablece, es decir, no se hace justicia en ninguno de los casos investigados, pues en el neopolicial la resolución del crimen pierde importancia y el investigador típico se configura como un personaje con una compleja psicología que «no siempre resuelve el misterio [...] y, cuando lo hace, deja otros muchos interrogantes sin resolver, lo que lo convierte en un antihéroe la mayoría de las veces consciente de sus limitaciones» (García, 2014, p. 77). A pesar de esto, Vilela sabe que Morel es culpable, pero, aun así, ante la casualidad del escape y posterior muerte del sospechoso Félix, decide trasladar la culpa a alguien que ya no puede defenderse. Por eso, Vilela parece actuar al margen de la ley y obviar los pasos propios de una investigación, se deja llevar por su propia intuición. Se trata, pues, de una investigación en la que son los lectores quienes tienen que descubrir las pistas que aparecen a medida que se desarrolla la historia, cuyo final no otorga la tranquilidad de atar cabos para llegar a una conclusión definitiva del crimen, sino que, por el contrario, resulta muy ambiguo y deja más interrogantes que respuestas.

En línea con lo anterior, los crímenes son interpretados en el neopolicial como un «accidente social, envuelto en la cotidianidad de las grandes nuevas ciudades» (Taibo II, 1979, p. 38), como un fenómeno social reiterativo, pues lo importante no es tanto la resolución del crimen, sino la denuncia del delito, de la corrupción y la violencia que lo envuelven. Por eso, el eje alrededor del cual se desarrollan los acontecimientos en El caso Morel no es la solución del crimen, pues en realidad, la novela inicia con el primer encuentro de Vilela y Morel dentro de la celda de este último y el caso parece resuelto casi desde el principio, cuando Matos incrimina al artista basado en el diario de Joana. 


\section{El arte apolíneo y el arte dionisíaco en El caso Morel, de Rubem Fonseca}

A partir de los anterior, es necesario afirmar que El caso Morel es una novela policíaca reflexiva, cuyos personajes, antes que buscar a un culpable, se buscan a sí mismos, incluso Morel busca comprender su actuar del pasado. Esta es una de las características constantes en la obra policial de Rubem Fonseca, pues, como lo señala González (2003), «los relatos no se estructuran para develar un crimen o buscar el culpable de un asesinato, sino para analizar qué es lo que sucede con los protagonistas, cómo mutan, a medida que se desarrollan las diversas situaciones» (p. 40). Una novela en la que criminales e investigadores pasan a segundo plano, pues más que descubrir a un culpable, «es una investigación sobre la literatura misma, sobre el trabajo del escritor, sus dudas, sus pasiones, su condena a vivir atrapado en la cárcel que significa el texto» (Tello, 2004, p. 6), cárcel que experimenta en carne propia Morel, no solo física, sino intelectualmente.

Podría decirse, entonces, que el lector se encuentra ante un policial que coincide con las características del arte dionisíaco: Vilela es un detective subjetivo, instintivo, transgresivo y pulsional que resuelve el caso de manera caótica e inconclusa. Además, el lector se encuentra ante una novela policiaca que no es homogénea, dado que su estructura no es armónica ni mesurada, sino que se nutre de diversos géneros textuales, como lo son los guiones cinematográficos, el género epistolar e, incluso, informes legales sobre la autopsia e investigación del asesinato de Heloísa.

Con relación a la presencia de intertextos en El caso Morel, Rocha Ribeiro (2012) señala dos tipos de citación: las acotaciones que se realizan en el libro de Morel y las constantes referencias a diversos autores y obras. Noguerol (2006) considera estos recursos del neopolicial como propios del posmodernismo, en el cual «se produce desde el punto de vista literario la revisión de las historias oficiales, el rechazo de los frescos narrativos y el recurso a la polifonía textual, estrategias con las que se intenta reflejar una realidad tan caótica como diversa» (p. 4). En este sentido, El caso Morel presenta una narración disruptiva en la que se realizan cambios constantes de narrador y en la que, incluso, dentro de la novela de Morel, se interrumpe la narración central para incluir las notas aisladas con las que parece comentar los sucesos descritos.

En cuanto a su forma estética se refiere, la novela se encuentra estructurada a modo de mise en abyme; la historia de Morel se encuentra inmersa dentro de la historia policíaca, la que a su vez se encuentra en un segundo plano para darle más importancia a la historia de vida y a las relaciones entre los personajes principales. Por eso, este fenómeno se evidencia en las fases de lectura que se presentan en la obra: por una parte, Vilela, como un lector empírico de la novela de Morel y, por otra, Morel, como lector de diversas obras (Rocha, 2012).

Por último, se destaca que, ante un final tan ambiguo, los lectores quedan con más dudas que respuestas, por lo cual pueden formular diferentes teorías para darle sentido a los acontecimientos, contrario a lo que ocurría en la novela policial clásica, en donde se daba un final cerrado.

\section{Consideraciones finales}

En suma, tanto La batalla de San Romano, como El baño turco y Le Cadeau son tres obras artísticas que se 


\section{El arte apolíneo y el arte dionisíaco en El caso Morel, de Rubem Fonseca}

refieren al atávico conflicto humano entre la sexualidad y la muerte, entre el instinto de preservación y el deseo de destrucción, tensiones que, como se destaca en el libro de Morel, están integradas en el hombre, quien tiene la necesidad de «amar, así como odiar. Destruir, y también crear y proteger» (Fonseca, 2015, p. 130). Si a esto se le añade la afinidad que desarrolla Joana al final de su existencia con el accionismo vienés, puede entenderse que la novela en sí destaca el conflicto entre los instintos de preservación y destrucción que tienen los personajes, siendo Joana, acorde a sus gustos artísticos, más propensa a la destrucción.

Si bien no todas las obras trascendentales en la novela son fieles exponentes del arte dionisíaco, los comentarios y las posibles interpretaciones que se pueden establecer a partir del juicio de los personajes logran generar una perspectiva de lectura completamente distinta de la tradicional, en donde se reflejan sus pulsiones y deseos más íntimos. De esta manera, la interpretación de Joana sobre El baño turco coincide con su deseo de entregarse con desenfreno al placer sexual y asocia con los personajes del cuadro su propia conducta masoquista.

Le Cadeau, por su parte, aparece en la obra como símbolo de la transición por la que atraviesan las mujeres de la década de los setenta en Brasil, como representación de la vagina dentata y de la sensación de inferioridad e inseguridad que siente el hombre con relación al nuevo rol que adoptaron las mujeres. Joana es una digna representante de esta nueva feminidad, pues, aunque establezca vínculos de dependencia hacia figuras masculinas — económico en el caso de su padre y afectivo en el de Paul Morel—, es una mujer libre que tiene el control sobre la relación, consiguiendo convencer a su pareja de hacer lo que ella desea.

Igualmente, la dependencia de Morel hacia el género femenino se manifiesta en sus múltiples amantes, en su impulso por aceptar cualquier invitación que provenga de una mujer y de llevarlas a todas a la cama, pero también en la conducta sumisa que establece con Joana, pues incluso llega a darle más importancia al placer de esta que al propio. Ahora bien, al tratarse de un período de cambio, las mujeres que aparecen en la novela «encontravamse possuindo e manifestando tanto as características de uma geração de rupturas quanto as marcas tradicionais, ainda inerentes à sociedade» (Gonçalves, 2008, p. 48).

Entonces, es posible afirmar, a partir del análisis de la relación que existe entre las obras mencionadas y la forma de actuar de Morel y Joana, que las experiencias y conocimientos artísticos que expresan influyen directamente sobre su comportamiento de tal manera que, inclusive, el criterio de Joana (Heloísa) evoluciona al mismo ritmo que sus gustos sexuales, con lo que su inclinación por «el arte de la visera» puede establecerse como un vaticinio del desenlace. Por su parte, Morel traiciona su criterio artístico y hace justo el tipo de obras que tanto manifiesta repudiar en busca de aceptación, tal como sucede en su relación con Joana, pues es también en busca de la aprobación de ella que cede a todas sus peticiones a pesar de no encontrarse tan cómodo con los gustos sexuales de ella.

Asimismo, puede afirmarse que en El caso Morel el arte aparece como una fuente de inspiración en el proceder cotidiano de estos dos personajes, hecho que los lleva a tener una vida igual de transgresora, destructiva e impulsiva que su ideal de arte. Incluso, de manera semejante al desarrollo de la investigación del crimen, el arte es interpretado a partir de las subjetividades de cada personaje, quienes reflejan en sus lecturas sus deseos más 
íntimos.

En cuanto al tratamiento del género policial, hay que destacar que su falta de rigurosidad y excesiva subjetivación de los hechos, su estructura desequilibrada, saturada de intertextos y diferentes géneros y, finalmente, la resolución inconclusa y caótica del caso, desembocan en un policial transgresor acorde a las características del arte dionisíaco. El final abierto de la novela da pie a que el lector se plantee diferentes interpretaciones del texto, incluso se puede considerar que el libro de Morel, que según él mismo no se trataba de un libro, sino de «"[...] solo una pequeña biografía, mal escrita. A story told by a fool..."» (p. 204), se encontraba inmerso en una novela cuyo autor fuera Vilela, pues, dado que los personajes vivencian una especie de proceso de unificación y en el cierre de la novela el detective se asume como uno mismo con Morel, generando un juego de espejos entre los dos, es válido preguntarse si el texto en su totalidad puede ser considerado simplemente como la narración ficticia del detective. De esta manera, el final de la novela, al igual que la pintura de Joana tienen «un clima siniestro, misterioso, excitante» (p. 67). 


\section{Referencias bibliográficas}

1. Amezcua, J. \& Sanz, N. (2005). Accionismo vienés: ¿Arte o violencia real? Revista Círculo hermenéutico, 5, 26-33.

2. Cardozo, Ó. (2009). La estética de la violencia sexual en Sade y en El caso Morel de Rubem Fonseca [tesis de Pregrado, Pontificia Universidad Javeriana]. Repositorio Institucional Javeriana. http://hdl.handle.net/10554/6406 3. Comellas, P. (2014). Rubem Fonseca e o policial noir. Abriu. Estudos de Textualidade do Brasil, Galicia e Portugal, 3, 51-69. http://hdl.handle.net/2445/65111

4. Follain, V. (2009). Rubem Fonseca y la literatura urbana. Taller de Letras, 44, 103-114.

5. Fonseca, R. (2015). El caso Morel. Tajamar Editores.

6. Fonseca, R. (1987). Bufo \& Spallanzani. (Losada, B. ed. y trad.). Epublibre.

7. Freud, S. (1992). Obras completas. Tomo XIV (Etcheverry, J. ed. y trad.). Amorrortu.

9. García, P. (2014). La novela neopolicial latinoamericana: una revuelta ético-estética del género. Cuadernos Americanos: Nueva Época, 2(148), 63-85.

10. Gonçalves, E. (2008). O paradoxo feminino em O caso Morel, de Rubem Fonseca. Revista Da Graduação, 2(1). https://revistaseletronicas.pucrs.br/ojs/index.php/graduacao/article/view/5009

11. González, M. (2003). Topógrafo de la sordidez: periodismo, pornografía y violencia en la obra de Rubem Fonseca. En Brú, J. (Comp.), Acercamientos a Rubem Fonseca. Premio Juan Rulfo. Universidad de Guadalajara, Centro Universitario de Ciencias Sociales y Humanidades.

12. Laplanche, J., Pontalis, J. y Lagache, D. (2004). Diccionario de psicoanálisis (Vol. 447). Paidós.

13. López, A. (2007). Violencia y literatura en «El cobrador» de Rubem Fonseca. En Las dos orillas: Actas del xv Congreso de la Asociación Internacional de Hispanistas. Monterrey, México, del 19 al 24 de julio de 2004 (pp. 393-404). Fondo de Cultura Económica.

14. Mendoza, E. (2003). El que a hierro mata, la va pasando: la narrativa de Rubem Fonseca. En Brú, J. (Comp.), Acercamientos a Rubem Fonseca. Premio Juan Rulfo. Universidad de Guadalajara, Centro Universitario de Ciencias Sociales y Humanidades.

15. Nietzsche, F. (2000). El nacimiento de la tragedia. Alianza Editorial.

16. Noguerol, F. (2006). Neopolicial latinoamericano: el triunfo del asesino. Ciberletras: Revista de Crítica Literaria y de Cultura, 15, 23-57.

17. Pimentel, L. (2003). Écfrasis y lecturas iconotextuales. Poligrafías. Revista de Literatura Comparada, 4, 205-215.

18. Rancière, J. (2011). El destino de las imágenes (M. Gajdowski, ed. y trad.). Prometeo Libros.

19. Rejany, M. (1999). O gênero feminino em Rubem Fonseca. Anuário de Literatura, 7(7), 169-189.

20. Ribeiro, J. (2001). O caso Morel: um caso de investigação literária. Signótica,13(1), 101-116. https://doi. 
El arte apolíneo y el arte dionisíaco en El caso Morel, de Rubem Fonseca

org/10.5216/sig.v13i1.7294

21. Robillard, V. (2011). En busca de la ecfrasis (un acercamiento intertextual). En Artigas, I. y González, S. (Eds.), Entre artes, entre actos, ecfrasis e intermedialidad (pp. 28-50). Bonilla Artigas Editores, UNAM.

22. Rocha, R. (2012). O caso Morel: um caso metaficcional. Signótica, 24(1), 173-189. https://doi.org/10.5216/ sig.v24i1.17923

23. Schrock, P. E. (1996). Man Ray’s Le Cadeau: The Unnatural Woman and the De-Sexing of Modern Man. Woman's Art Journal.

24. Soláns, P. (2000). Accionismo vienés (Vol. 5). Editorial Nerea.

25. Taibo II, P. I. (1987). La «otra» novela policíaca. Los Cuadernos del Norte: Revista Cultural de la Caja de Ahorros de Asturias, 8(41), 36-41.

26. Tello, R. (1993). La violencia como estética de la misantropía: cuatro acercamientos a la obra de Rubem Fonseca [tesis de Maestría, Universidad Nacional Autónoma de México]. Repositorio Institucional UNAM. https://repositorio.unam.mx/contenidos/384262

27. Tello, R. (2004). La violencia como estética de la misantropía en la obra de Rubem Fonseca. En R. Tello (ed. y trad.), Los mejores relatos. Alfaguara.

28. Tornquist, H. (2007). O romance e a violência urbana. Outra Travessia, (6), 127-136. 